\title{
Annex 1: Programme of the Seminar
}

\section{Thursday 14 February 2002}

09.00 Registration

09.30 Welcome, Abdul Waheed Khan, Assistant Director General for Communication \& Information, UNESCO

09.45 Introduction, Kurt Molholm, President ICSTI

10.15 The CODATA interest, CODATA activities and developments, William Anderson, US Representative, CODATA Data Archiving Working Group

10.45 Questions/clarifications

10.50 Coffee

11.15 ICSU activities and developments, Sir Roger Elliot, Chairman, ICSU Press

11.45 Digital preservation; overview of current developments, Gail Hodge, Information International Associates

12.30 IUPAP initiatives, report from the Lyon Workshop, Claus Montonen, European Physical Society

13.00 Lunch

14.00 STM Members; viewpoint and developments, Karen Hunter, Elsevier Inc.

14.30 Developments in related fields:

- Metadata and pre-print archives, Leona Carpenter, UKOLN, UK

- Deposit Libraries, Johan Steenbakkers, National Library, The Netherlands

- Digital Object Identifiers, Norman Paskin, DOI Foundation

15.30 Tea

16.00 Specific examples and issues

- JSTOR, Bruce Heterick, JSTOR, New York

- Preserving our Cultural Heritage, Yola de Lusenet, Royal Netherlands Academy of Arts and Sciences; Abdelaziz Abid, UNESCO

17.00 Discussion and Close of Day 1

\section{Friday 15 February 2002}

10.00 Review of Day 1

10.30 Research projects underway and planned, Neil Beagrie, UK JISC Digital Preservation Focus

11.00 Coffee

11.30 Next steps:

- Standardisation activities, Gail Hodge

- Metadata and preservation, Deborah Woodyard, British Library

- Liaison between different interest groups, Sally Morris, APLSP

- Guidelines for digital preservation actions; the requirements for guidelines, Bernard Smith, Head of Unit, Cultural Heritage Applications, Information Society DG, European Commission 
12.30 Lunch

14.00 Proposed actions - Establishing working parties:

- Guidelines development

- Liaison between different interests

- Others

16.00 Tea

16.30 Timetable for further actions and wrap-up

17.30 Close 